Sādhanā Vol. 36, Part 1, February 2011, pp. 73-85. (C Indian Academy of Sciences

\title{
Optimum design of laminated composite under axial compressive load
}

\author{
N G R IYENGAR ${ }^{1, *}$ and NILESH VYAS ${ }^{2}$ \\ ${ }^{1}$ Department of Aerospace Engineering, Jain University, Jain Global Campus, \\ Jakkasandra Post, Bangalore 562 112, India \\ ${ }^{2}$ Hindustan Petroleum Corporation Limited (HPCL), Mangalore LPG Import \\ Facility, Mangalore 575 006, India \\ e-mail: ngri@iitk.ac.in; nileshvyas.nv@gmail.com
}

MS received 28 April 2010; revised 27 August 2010; accepted 17 September 2010

\begin{abstract}
In the present study optimal design of composite laminates, with and without rectangular cut-out, is carried out for maximizing the buckling load. Optimization study is carried out for obtaining the maximum buckling load with design variables as ply thickness, cut-out size and orientation of cut-out with respect to laminate. Buckling load is evaluated using a 'simple higher order shear deformation theory' based on four unknown displacements $u, v, w_{b}$ and $w_{s} . \mathrm{A} \mathrm{C}^{1}$ continuous shear flexible finite element based on HSDT model is developed using Hermite cubic polynomial. It is observed that for thick anti-symmetric laminates, the non-dimensional buckling load decreases with increase in aspect ratio and increase in fibre orientation angle. There is a decrease in the non-dimensional buckling load of symmetric laminate in the presence of cut-out.
\end{abstract}

Keywords. Composite laminate; genetic algorithm; buckling; optimum design; finite element.

\section{Introduction}

Buckling of structural elements like columns, plates, shells, etc. whether slender or thin is an important phenomenon and certainly has to be looked into design phase itself. In aerospace structures generally thin walled members are used from the weight consideration. Hence they are prone to buckling under in-plane loads. Cut-outs are generally made in the structures either to lighten the structures or to carry cables, etc. Two survey articles by Leissa $(1981,1987)$ deal extensively with buckling of laminated composite plates. Results for both the symmetric and anti-symmetric modes of buckling of anti-symmetric cross-ply plates with various aspect ratios have been presented in a graphical form by Hui (1984). Studies conducted by Reissner (1945), Whitney (1969) and Whitney \& Pagano (1970) show that transverse shear effect is quite significant in layered composite plates due to high ratio of in-plane elastic modulus to transverse shear modulus. They predict better results than the classical lamination theory. However, the error in

*For correspondence 
the solution increases with increase in plate thickness to side ratio. To account for a better representation of the shear distribution through the thickness, (Reddy 1984) proposed a higher order shear deformation theory. Reddy (1990) presented a general non-linear third order theory for plates with moderate thickness. Reddy (2006) in his recent book discussed the response of composite plates and shells. A simplified higher order theory proposed by Lim et al (1988) involves only four unknowns instead of five by Reddy (1984). Singh (1993) and Chakraborty (2003) used this model for the response of laminated composite beams and plates.

Srivatsa \& Murthy (1991) presented a parametric study of the compression buckling behaviour of stress loaded composite plate with a central circular cut-out. Jain \& Kumar (2003) analysed the post buckling response of square laminates with a central circular/elliptical cut-out. Prabhakara \& Datta (1997) studied the vibration and buckling behaviour of plates with centrally located cutouts. Anil (2004) analysed laminated plates for initial buckling with cut-outs under uni-axial and biaxial compressive and shear in-plane loading, using simple HSDT.

Genetic algorithm (GA) has become a powerful and robust tool for function optimization (Goldberg 1989, Deb 2001). These algorithms are computational simple but powerful in their search for improvement in successive generations (Nagendra et al 1992). GA mimics some of the natural process observed in natural evolution. The basic techniques of GA are designed to simulate mechanism of population genetics and natural laws of survival. One of the big advantages of GA is that it does not require differentiability of either objective function or constraints (Nagendra et al 1992). The constraint handling capacity of GA is better than classical optimization techniques because of population based approach (Callahan \& Weeks 1992). Nagendra et al (1992) studied the buckling optimization of laminate sequence with strain constraints. Callahan \& Weeks (1992) studied the optimum design of composite laminates for maximizing laminate strength and stiffness with fixed number of plies. They employed tournament selection scheme in the selection process. Single point crossover is used with a crossover probability of $P_{c}=0.75$ and mutation probability of 0.1 per cent. Kogiso et al (1994) applied GA with memory for design of minimum thickness composite laminates subject to strength, buckling and ply contiguity conditions.

Muc \& Gurba (2001) used GA for layout optimization of composite structures with finite element optimization of objective function. Sivakumar et al (1999) used GA for optimizing the composite laminates with cut-outs undergoing large amplitude oscillations. They compared GA with many other algorithms and found GA to be better in almost every aspect.

It is observed that most researchers have used closed form solution to solve the bending, buckling or vibration problems. FEM has proved to be a good approximation for structures for which closed form solution is not possible. In the study presented here, optimization of composite laminates is carried out for maximizing the buckling load with and without cut-out using GA. The effects of various parameters such as aspect ratio, cut-out size, crossover and mutation probabilities on the buckling load are investigated.

\section{Formulation}

\subsection{Constitutive relations}

This section deals with details of the plate theory proposed by (Lim et al 1988) for isotropic plates and extended to composite laminates. The displacement field includes plate theory and first order shear deformation theory as subsets and accounts for parabolic variation of the transverse shear strains as well as the surface boundary conditions of zero transverse shear stresses at the top and bottom surfaces of the laminate. 
The coordinate system used is shown in figure 1 . The displacements $u(x, y, z), v(x, y, z)$ and $w(x, y, z)$ at any point in the laminate is written as

$$
\begin{aligned}
& u(x, y, z)=u_{0}(x, y)-z \frac{\partial w_{b}}{\partial x}(x, y)+z^{2} \phi_{x}(x, y)+z^{3} \psi_{x}(x, y) \\
& v(x, y, z)=v_{0}(x, y)-z \frac{\partial w_{b}}{\partial y}(x, y)+z^{2} \phi_{y}(x, y)+z^{3} \psi_{y}(x, y) \\
& w(x, y, z)=w_{b}(x, y)+w_{s}(x, y),
\end{aligned}
$$

where $u_{0}, v_{0}, w$ denote the displacements of a point on the mid-plane, and $\Psi_{x}$ and $\Psi_{y}$ are the warping of the normal to the mid-plane about the $\mathrm{Y}$ and $\mathrm{X}$ axes respectively. The transverse displacement component $w_{b}$ is such that its derivatives are numerically equal to the rotation of the cross section and $w_{s}$ is the displacement due to the effect of transverse shear deformation of the cross section. The von-Karman type non-linear strain displacement relations is written as

$$
\begin{aligned}
\varepsilon_{x}= & \frac{\partial u_{0}}{\partial x}+\frac{1}{2}\left(\frac{\partial w_{b}}{\partial x}+\frac{\partial w_{s}}{\partial x}\right)^{2}-z \frac{\partial^{2} w_{b}}{\partial x^{2}}+z^{2} \frac{\partial \phi_{x}}{\partial x}+z^{3} \frac{\partial \psi_{x}}{\partial x} \\
\varepsilon_{y}= & \frac{\partial v_{0}}{\partial y}+\frac{1}{2}\left(\frac{\partial w_{b}}{\partial y}+\frac{\partial w_{s}}{\partial y}\right)^{2}-z \frac{\partial^{2} w_{b}}{\partial y^{2}}+z^{2} \frac{\partial \phi_{x}}{\partial y}+z^{3} \frac{\partial \psi_{x}}{\partial y} \\
\varepsilon_{z}= & 0 \\
\gamma_{x y}= & \frac{\partial u_{0}}{\partial y}+\frac{\partial v_{0}}{\partial x}+\left(\frac{\partial w_{b}}{\partial x}+\frac{\partial w_{s}}{\partial x}\right)\left(\frac{\partial w_{b}}{\partial y}+\frac{\partial w_{s}}{\partial y}\right)-2 z \frac{\partial^{2} w_{b}}{\partial x \partial y}+z^{2}\left(\frac{\partial \phi_{y}}{\partial x}+\frac{\partial \phi_{x}}{\partial y}\right) \\
& +z^{3}\left(\frac{\partial \psi_{y}}{\partial x}+\frac{\partial \psi_{x}}{\partial y}\right) \\
\gamma_{x z}= & \frac{\partial w_{s}}{\partial x}+2 z \phi_{x}+3 z^{2} \psi_{x} \\
\gamma_{y z}= & \frac{\partial w_{s}}{\partial y}+2 z \phi_{y}+3 z^{2} \psi_{y} .
\end{aligned}
$$

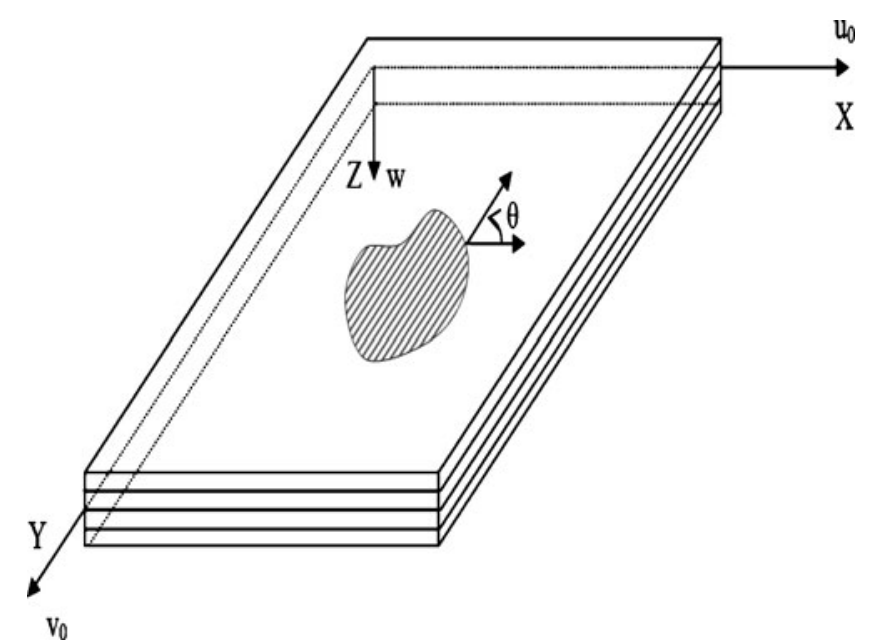

Figure 1. Coordinate system for the laminate. 
Incorporating the conditions that transverse shear stresses vanish at the top and bottom faces of the laminate, the resulting displacement field is given as

$$
\begin{aligned}
& u(x, y, z)=u_{0}(x, y)-z \frac{\partial w_{b}}{\partial x}-\frac{4 z^{3}}{3 h^{2}} \frac{\partial w_{s}}{\partial x} \\
& v(x, y, z)=v_{0}(x, y)-z \frac{\partial w_{b}}{\partial y}-\frac{4 z^{3}}{3 h^{2}} \frac{\partial w_{s}}{\partial y} \\
& w(x, y, z)=w_{b}(x, y)+w_{s}(x, y) .
\end{aligned}
$$

It can be shown that the present formulation degenerates to first order shear deformation theory by suitably dropping the higher order terms and incorporating the appropriate shear correction factors. The classical laminate theory can be derived from the present theory by equating $w_{s}$ to zero.

The stress-strain relations for the $k^{\text {th }}$ lamina in the material coordinate axes are given as (Jones 1975):

$$
\left\{\begin{array}{c}
\sigma_{L} \\
\sigma_{T} \\
\tau_{L T} \\
\tau_{L T^{\prime}} \\
\tau_{T T^{\prime}}
\end{array}\right\}=\left[\begin{array}{ccccc}
Q_{11} & Q_{12} & 0 & 0 & 0 \\
Q_{12} & Q_{22} & 0 & 0 & 0 \\
0 & 0 & Q_{66} & 0 & 0 \\
0 & 0 & 0 & Q_{44} & 0 \\
0 & 0 & 0 & 0 & Q_{55}
\end{array}\right]\left\{\begin{array}{c}
\varepsilon_{L} \\
\varepsilon_{T} \\
\gamma_{L T} \\
\gamma_{L T^{\prime}} \\
\lambda_{T T^{\prime}}
\end{array}\right\} .
$$

Eq. (4) is rewritten for each lamina depending on the fibre orientations. Using these transformed constitutive equations and integrating over the laminate thickness, the stress resultants, stress couples, transverse shear resultants and higher order stress couples per unit length for the laminate are;

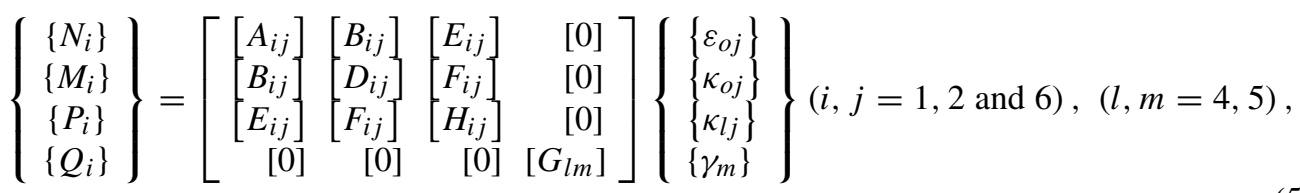

where $\left\{\varepsilon_{0}\right\}$ are the mid-surface strains, $\left\{\kappa_{0}\right\}$ are the mid-surface bending and twisting curvatures, $\left\{\kappa_{l}\right\}$ are the higher order terms and $\{\gamma\}$ are the transverse shear slope (for details of the derivation of various elements of Eq. (5), see Vyas 2005).

\subsection{Finite element formulation}

In the present formulation, there are four variables namely, two in-plane displacements and two out-of-plane displacements. Four-noded rectangular elements are used to represent the entire domain of the laminate. A $C^{1}$ continuous shear flexible element is developed using Hermite interpolation formulae as suggested by Bogner et al (1966). A typical mesh generated over the entire laminate with centrally located cut-out is shown in figure 2 . The nodal displacement vector $\{\delta\}$ is written in terms of the four unknown displacements as

$$
\{\delta\}^{T}=\left\{\begin{array}{llll}
u_{0} & v_{0} & w_{b} & w_{s}
\end{array}\right\} .
$$




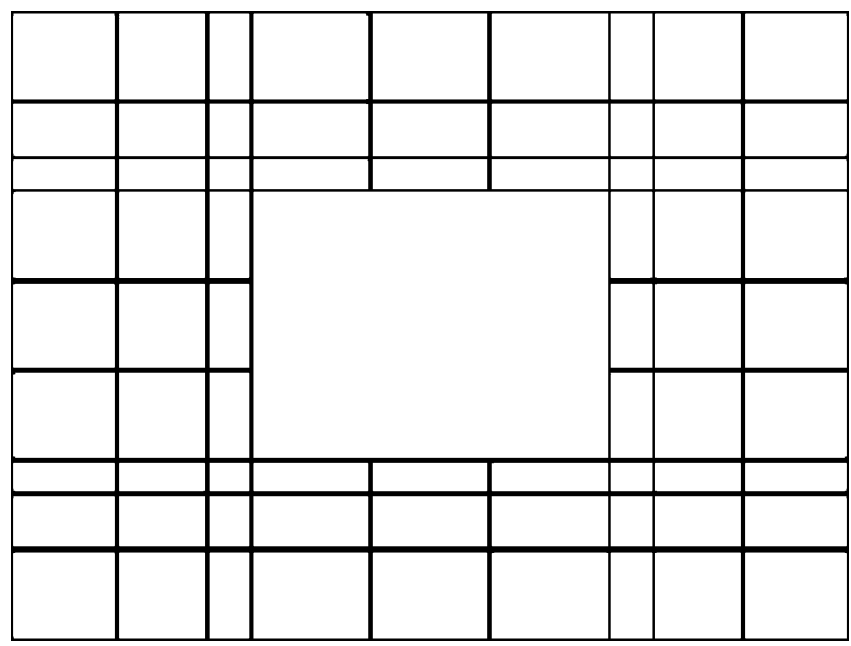

Figure 2. Graded mesh for a rectangular domain with a cut-out.

For any element the field variables can be written in terms of the shape functions and nodal variables as:

$$
\begin{aligned}
& u_{0}(x, y)=\sum_{i=1}^{4} N_{i}^{\prime} u_{0 i}+\sum_{i=1}^{4} N_{i+4}^{\prime}\left(\frac{\partial u_{0}}{\partial x}\right)_{i}+\sum_{i=1}^{4} N_{i+8}^{\prime}\left(\frac{\partial u_{0}}{\partial y}\right)_{i}+\sum_{i=1}^{4} N_{i+12}^{\prime}\left(\frac{\partial^{2} u_{0}}{\partial x \partial y}\right)_{i} \\
& v_{0}(x, y)=\sum_{i=1}^{4} N_{i}^{\prime} v_{0 i}+\sum_{i=1}^{4} N_{i+4}^{\prime}\left(\frac{\partial v_{0}}{\partial y}\right)_{i}+\sum_{i=1}^{4} N_{i+8}^{\prime}\left(\frac{\partial v_{0}}{\partial y}\right)_{i}+\sum_{i=1}^{4} N_{i+12}^{\prime}\left(\frac{\partial^{2} v_{0}}{\partial x \partial y}\right)_{i} \\
& w_{b}(x, y)=\sum_{i=1}^{4} N_{i}^{\prime} w_{b i}+\sum_{i=1}^{4} N_{i+4}^{\prime}\left(\frac{\partial w_{b}}{\partial x}\right)_{i}+\sum_{i=1}^{4} N_{i+8}^{\prime}\left(\frac{\partial w_{b}}{\partial y}\right)_{i}+\sum_{i=1}^{4} N_{i+12}^{\prime}\left(\frac{\partial^{2} w_{b}}{\partial x \partial y}\right)_{i} \\
& w_{s}(x, y)=\sum_{i=1}^{4} N_{i}^{\prime} w_{s i}+\sum_{i=1}^{4} N_{i+4}^{\prime}\left(\frac{\partial w_{s}}{\partial x}\right)_{i}+\sum_{i=1}^{4} N_{i+8}^{\prime}\left(\frac{\partial w_{s}}{\partial y}\right)_{i}+\sum_{i=1}^{4} N_{i+12}^{\prime}\left(\frac{\partial^{2} w_{s}}{\partial x \partial y}\right)_{i} .
\end{aligned}
$$

In Eq (7), $u_{0 i}, v_{0 i}, w_{b i}, w_{s i}$, are the sixteen degrees of freedom per node, $N_{i}^{\prime}$ s are the element shape functions in local coordinates. Reddy (2004) gives the shape functions in natural coordinates.

The boundary conditions applied along the edges of the laminate are as follows:

simply supported along all the edges: $w_{b}=w_{s}=0$,

clamped along all the edges: $w_{b}=w_{s}=w_{b, n}=w_{s, n}=0$.

The investigations are confined to the initial buckling of the laminate. Therefore, $w_{b}$ and $w_{s}$ are assumed to be very small. 
The undeformed configuration of the laminate is denoted by $\Omega$ and its boundary by $\partial \Omega$. The infinitesimal strain is defined in terms of the Cartesian components of the displacements $\left(u_{i}, i=1,2\right.$ and 3$)$

$$
\varepsilon_{i j}=\frac{1}{2}\left(u_{i j}+u_{j i}\right),
$$

which is the simplification of the Green-Lagrange strains defined by

$$
\Xi_{i j}=\varepsilon_{i j}+\frac{1}{2}\left(\mathrm{u}_{\alpha, i} \times \mathrm{u}_{\alpha, \mathrm{j}}\right)
$$

The simplification is justified by the assumption that $\left|\mathrm{u}_{\alpha, \mathrm{i}}\right| \ll 1$ and hence the product terms are negligible in relation to $\mathrm{u}_{i j}$. The constitutive equation is

$$
\sigma_{i j}=\sigma_{i j}^{0}+C_{i j k l} \varepsilon_{k l}
$$

In which $\sigma_{i j}^{0}$ is the pre-existing stress state independent of $\mathrm{u}_{i}$ and $C_{i j k l}$ is the tenor of the elastic moduli of the material. An important property of $\sigma_{i j}^{0}$ is that it is in equilibrium with the corresponding tractions $T_{i}^{0}=\sigma_{i j}^{0} n_{j}$ in the sense (Paul 1998).

$$
\frac{1}{2} \int_{\Omega} \sigma_{i j}^{0}\left(\mathrm{u}_{i, j}+\mathrm{u}_{j, i}\right) \mathrm{d} V=\int_{\partial \Omega} T_{i}^{0} \mathrm{u}_{i} \mathrm{~d} A \text { for all } \mathrm{u}_{i} \in \mathrm{E}(\Omega),
$$

where $\mathrm{d} V$ and $\mathrm{d} A$ represent the differential volume and differential area respectively. $\mathrm{E}(\Omega)$ is the space of kinematically admissible perturbations. When the reference configuration is stress free, then the potential energy is defined as

$$
\Pi(\mathrm{u})=\frac{1}{2} \int_{\Omega} C_{i j k l} \varepsilon_{i j} \varepsilon_{k l} \mathrm{~d} V-\int_{\Omega} T_{i} \mathrm{u}_{i} \mathrm{~d} A .
$$

The exact solution minimizes $\Pi$ on the set of all kinematically admissible functions denoted by $\mathrm{E}(\Omega)$. When the reference configuration is not stress free, then the work done by the stress $\sigma_{i j}^{0}$ due to nonlinear strain terms may not be negligible. The potential energy expression becomes

$$
\Pi(\mathrm{u})=\frac{1}{2} \int_{\Omega} C_{i j k l} \varepsilon_{i j} \varepsilon_{k l} \mathrm{~d} V+\frac{1}{2} \int_{\Omega} \sigma_{i j}^{0} \mathrm{u}_{\alpha, j} \mathrm{u}_{\alpha, j} \mathrm{~d} V-\int_{\Omega} T_{i} \mathrm{u}_{i} \mathrm{~d} A .
$$

The first term in Eq. (13) represents the internal strain energy and the second term represents the work done by the initial stresses due to the nonlinear strain terms. The work done by $\sigma_{i j}^{0}$ due to the linear strain terms is cancelled by the work done by $T_{i}^{0}$ in the sense of Eq. (12).

The exact solution to the problem is obtained by minimizing the total potential energy $\Pi$. This leads to the generalized finite element formulation which can be expressed as

$$
\left[[K]-\left[K_{g}\right]\right]\{\bar{\delta}\}=0 .
$$

The elastic stiffness and geometric stiffness matrices are obtained in the usual manner. 


\subsection{Optimization formulation}

Genetic algorithm (GA) is used for optimizing the buckling load. The optimization problem is defined in the following manner.

$$
\begin{aligned}
& \text { Maximize } \quad \begin{array}{l}
\lambda \text { (buckling load) } \\
\text { Subject to } \quad \theta_{i} \quad \in\left\lfloor \pm 60^{\circ}, \pm 45^{\circ}, \pm 30^{\circ}, 0^{\circ}, 90^{\circ}\right\rfloor \\
\qquad \sum_{i=1}^{N} h_{i}=h \\
h_{l} \leq h_{i} \leq h_{u} .
\end{array}
\end{aligned}
$$

The buckling load $\lambda$ is obtained from Eq. (14).

2.3a Evaluation of fitness: If the constraint is not violated, the fitness is the buckling load obtained by solving the characteristic equation of Eq. (14). If the constraint is violated, a very high penalty factor of the order of 100,000 is imposed. This is expressed as

if the constraint is not violated,

$$
\text { Fitness }=\text { buckling load } \lambda \text { or else }
$$

$$
\text { Fitness }=\frac{\text { Buckling load }}{\left(10^{5} \times \mid \text { Prescribed thickness }- \text { Evaluated total thickness } \mid\right)}
$$

2.3b Coding in genetic algorithm: The ply angles and the group ply thickness are coded in strings. A ten layer laminate is considered for the study. The ply angles are coded from 1 to 8 . These stand for the stacking sequence, $-60^{\circ},-45^{\circ},-30^{\circ}, 0^{\circ}, 30^{\circ}, 45^{\circ}, 60^{\circ}, 90^{\circ}$ respectively. The laminate thickness is considered in multiples of ten and is generated within the specified bounds on individual ply thickness.

2.3c Convergence criteria: The convergence of the solution to the optimum value is decided by

- The constraint value at the optimum point

- Repetition of same value with different starting values

- Repetition of the population in final generation.

2.3d Optimization study: Problem 1: For optimization study of the laminate without cut-out, the following data have been considered.

Material:

$E_{L}=130 \mathrm{GPa},\left(E_{L} / E_{T}\right)=13,\left(G_{L T} / E_{T}\right)=0.5,\left(G_{L T^{\prime}} / E_{T}\right)=0.5,\left(G_{T T^{\prime}} / E_{T}\right)=$ $0.5, v_{L T}=0.35$

Number of plies: 10

Boundary condition: all edges are simply supported

Objective function: Maximize buckling load. 
Constraints:

$$
\begin{array}{r}
\theta_{i} \in\left\lfloor \pm 60^{\circ}, \pm 45^{\circ}, \pm 30^{\circ}, 0^{\circ}, 90^{\circ}\right\rfloor \\
\sum_{1}^{10} h_{i}=2 \mathrm{~mm}, \quad 0.1 \leq h_{i} \leq 0.4
\end{array}
$$

GA Parameters:

Maximum number of generations $=100$

Population size $=50$

Probability of cross-over $=0.80$

Probability of mutation $=0.02$

Optimized results:

Optimal code of the laminate: $\left[-45^{\circ} / 30^{\circ} /-45^{\circ} / 0_{2}^{\circ}\right]_{S}$

Ply thickness $=[0.1 / 0.2 / 0.2 / 0.3 / 0.2]_{s}$.

Problem 2: For optimization study of the laminate with rectangular cut-out, the following data has been considered.

Material:

$E_{L}=200 \mathrm{GPa},\left(E_{L} / E_{T}\right)=40,\left(G_{L T} / E_{T}\right)=0.6,\left(G_{L T} / E_{T}\right)=0.6,\left(G_{T T} / E_{T}\right)=$ $0.5, v_{L T}=0.25$

Number of plies: 8

Boundary conditions: all edges simply supported

Objective function: Maximize buckling load.

Constraints:

$$
\begin{aligned}
& \theta_{i} \in\left\lfloor \pm 60^{\circ}, \pm 45^{\circ}, \pm 30^{\circ}, 0^{\circ}, 90^{\circ}\right\rfloor \\
& \sum_{1}^{8} h_{i}=1.6 \mathrm{~mm} \\
& 0.1 \leq h_{i} \leq 0.4 \\
& 0.2 \leq \mathrm{c} / \mathrm{a} \leq 0.8 .
\end{aligned}
$$

GA parameters:

Maximum number of generations: 50

Population size $=40$

Probability of cross over $=0.85$

Probability of mutation $=0.02$.

Optimized results:

Optimal code of the laminate $\left[-30^{\circ} / 45^{\circ} /-45^{\circ} / 30^{\circ}\right]_{S}$

Ply thickness: $[0.1 / 0.2 / 0.2 / 0.3]_{s}$

Optimum c/a ratio: 0.2 .

\section{Results and discussion}

Both symmetric and anti-symmetric laminates, with simply supported and clamped edges are considered for computation. The validation of the genetic algorithm code is carried out on three sets of problems for which results are available. The tests problems are hard globalization 
Table 1. Comparison of optimized results for variable thickness laminates with uniform thickness laminates.

\begin{tabular}{|c|c|c|c|c|c|c|}
\hline \multirow[b]{3}{*}{ S. No } & \multicolumn{5}{|c|}{$\mathrm{a} / \mathrm{b}=1$ and $\mathrm{a} / \mathrm{h}=100$} & \multirow[b]{3}{*}{$\begin{array}{c}\% \\
\text { Increase }\end{array}$} \\
\hline & \multirow[b]{2}{*}{$\begin{array}{c}\text { Ply } \\
\text { orientations }\end{array}$} & \multicolumn{2}{|c|}{ Unoptimized results } & \multicolumn{2}{|c|}{ Optimized results } & \\
\hline & & $\begin{array}{c}\text { ND } \\
\text { Buckling } \\
\text { load with } \\
\text { constant } \\
\text { thickness }\end{array}$ & $\begin{array}{c}\text { Thickness } \\
(\mathrm{mm})\end{array}$ & $\begin{array}{c}\text { ND } \\
\text { Buckling } \\
\text { load with } \\
\text { variable } \\
\text { thickness }\end{array}$ & $\begin{array}{c}\text { Thickness } \\
(\mathrm{mm})\end{array}$ & \\
\hline 1 & {$[30 /-30 / 30 /-30] \mathrm{s}$} & 56.080 & {$[0.2 / 0.2 / 0.2 / 0.2] \mathrm{s}$} & 59.283 & {$[0.1 / 0.2 / 0.2 / 0.3] \mathrm{s}$} & 5.7 \\
\hline 2 & {$[45 /-45 / 45 /-45] \mathrm{s}$} & 63.014 & {$[0.2 / 0.2 / 0.2 / 0.2] \mathrm{s}$} & 67.010 & {$[0.1 / 0.2 / 0.2 / 0.3] \mathrm{s}$} & 6.3 \\
\hline 3 & {$[60 /-60 / 60 /-60] \mathrm{s}$} & 50.173 & {$[0.2 / 0.2 / 0.2 / 0.2] \mathrm{s}$} & 53.851 & {$[0.1 / 0.2 / 0.2 / 0.3] \mathrm{s}$} & 7.3 \\
\hline 4 & {$[90 / 0 / 30 /-30] \mathrm{s}$} & 38.670 & {$[0.2 / 0.2 / 0.2 / 0.2] \mathrm{s}$} & 43.138 & {$[0.1 / 0.1 / 0.3 / 0.3] \mathrm{s}$} & 11.5 \\
\hline 5 & {$[90 / 0 / 45 /-45] \mathrm{s}$} & 39.575 & {$[0.2 / 0.2 / 0.2 / 0.2] \mathrm{s}$} & 45.694 & {$[0.1 / 0.1 / 0.3 / 0.3] \mathrm{s}$} & 15.4 \\
\hline 6 & {$[90 / 0 / 60 /-60] \mathrm{s}$} & 38.691 & {$[0.2 / 0.2 / 0.2 / 0.2] \mathrm{s}$} & 43.182 & {$[0.1 / 0.2 / 0.3 / 0.3] \mathrm{s}$} & 11.6 \\
\hline 7 & {$[0 / 30 / 0 / 30] \mathrm{s}$} & 40.267 & {$[0.2 / 0.2 / 0.2 / 0.2] \mathrm{s}$} & 40.526 & {$[0.1 / 0.2 / 0.3 / 0.2] \mathrm{s}$} & 0.64 \\
\hline 8 & {$[0 / 45 / 0 / 45] \mathrm{s}$} & 41.524 & {$[0.2 / 0.2 / 0.2 / 0.2] \mathrm{s}$} & 42.063 & {$[0.1 / 0.2 / 0.3 / 0.2] \mathrm{s}$} & 1.3 \\
\hline 9 & {$[0 / 60 / 0 / 60] \mathrm{s}$} & 39.928 & {$[0.2 / 0.2 / 0.2 / 0.2] \mathrm{s}$} & 40.256 & {$[0.1 / 0.2 / 0.3 / 0.2] \mathrm{s}$} & 0.82 \\
\hline
\end{tabular}

problems on which most conventional local optimization algorithms would fail miserably (Paul 1998).

For the response of square laminate with a square cut-out, the following laminate sequencing was studied $\left(\left[45^{\circ} /-45^{\circ} / 45^{\circ} /-45^{\circ}\right]_{S}\right.$ and $\left.\left[0^{\circ} / 90^{\circ} / 0^{\circ} / 90^{\circ}\right]_{S}\right)$ for simply supported boundary conditions. From the analysis of the results it is observed that for simply supported boundary conditions, the non-dimensional buckling load remains fairly constant for a cutout ratio greater than 0.4 . Similar trend is not observed in the case of clamped boundary condition.

Table 1 shows the results obtained for a uniform and variable thickness laminate along with unoptimized and optimized non-dimensional buckling load. It is seen that with constraint on overall thickness, variable thickness laminate is better than uniform thickness.

Some typical results are presented in this paper. Figures 3 and 4 show the variation of fibre orientation $\theta$ with optimized non-dimensional buckling load for a square laminate without

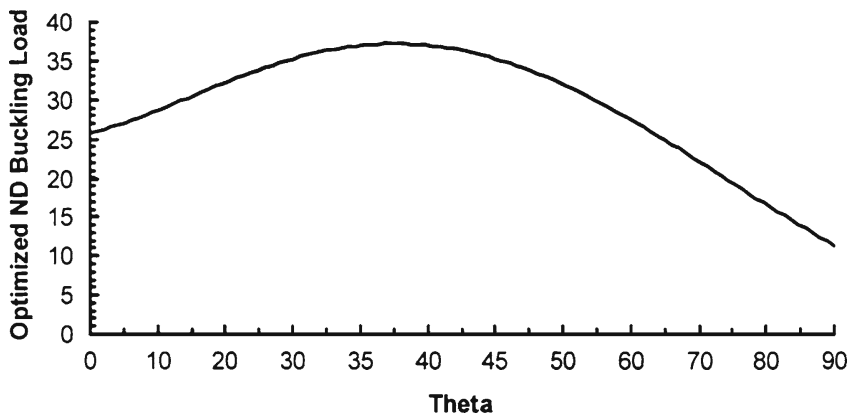

Figure 3. Optimized non-dimensional buckling load versus fibre orientation for a square laminate without cut-out. $(a / h=10)$. 


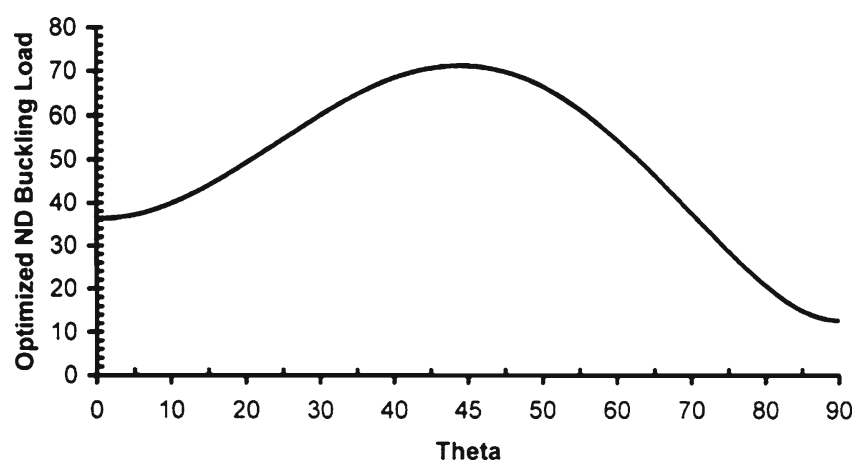

Figure 4. Optimized non-dimensional buckling load versus fibre orientation for a square laminate without cut-out. $(a / h=100)$.

cut-out for $a / h$ ratios of 10 and 100 respectively. From figure 3 it is observed that for $a / h=100$, $\theta_{\text {cric }}$ is approximately $45^{\circ}$ and as the thickness of the laminate increases $\theta_{\text {cric }}$ reduces as seen in figure 4 for $a / h=10$. Figures 5 and 6 show the results for a square laminate with rectangular cut-out with $a / h=10$ and 100 respectively. $\theta_{\text {cric }}$, remains approximately the same as for laminates without cut-out. However, the maximum buckling load occurs when $(\mathrm{c} / \mathrm{a}=\mathrm{d} / \mathrm{b}=0.2)$. Results have been computed for both thin and thick laminates and with and without cut-outs for various aspect ratios. It was observed that the non-dimensional buckling load decreases as the laminates become thicker. Further, the fibre orientation $\theta_{\text {cric }}$ (the value of $\theta$ at which the maximum buckling load occurs) decreases as the laminates become thick.

Figures 7 and 8 show the effect of crossover probability and mutation probability on the convergence of the solution for a laminate without cut-out. From figure 8, it is observed that high mutation probability gives better solution for earlier generations only, but at the same time it destroys the good solution which is already created. At higher mutation probability the initial convergence is faster. However, as the number of generations is increased the convergence to global optimum is lost.

Figure 9 shows the effect of crossover probability on the convergence of the solution for a laminate with cut-out. The solution improves with higher crossover probability. However, the rate of convergence is slow.

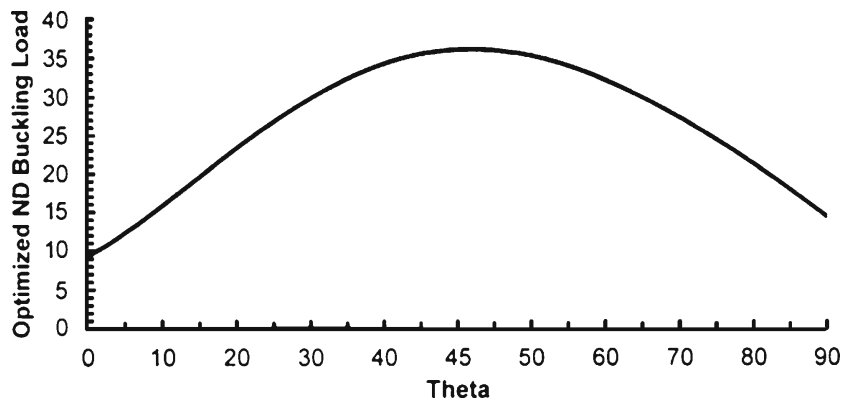

Figure 5. Optimized non-dimensional buckling load versus fibre orientation for a square laminate with cut-out. $(a / h=10$, optimum c/a $=\mathrm{d} / \mathrm{b}=0.2)$. 


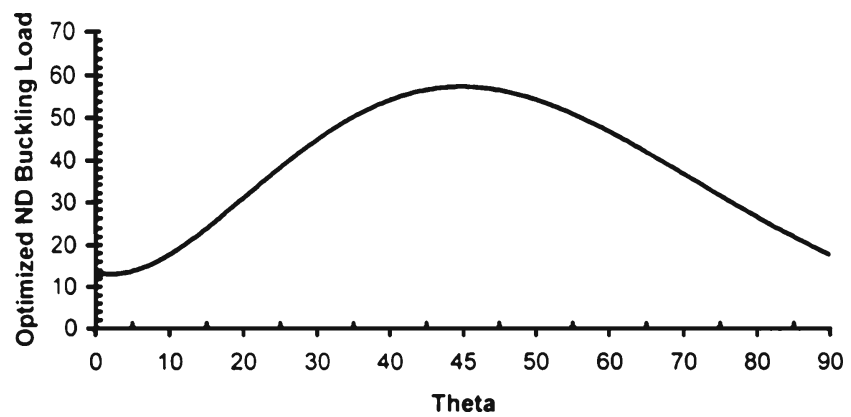

Figure 6. Optimized non-dimensional buckling load versus fibre orientation for a square laminate with cut-out. $(a / h=100$, optimum $\mathrm{c} / \mathrm{a}=\mathrm{d} / \mathrm{b}=0.2)$.

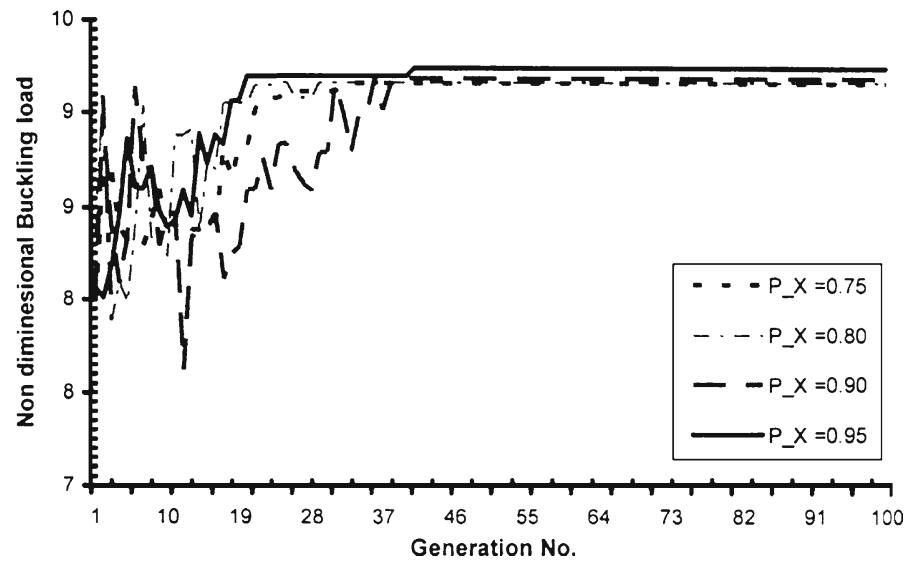

Figure 7. Non-dimensional buckling load versus the number of generation (square plate).

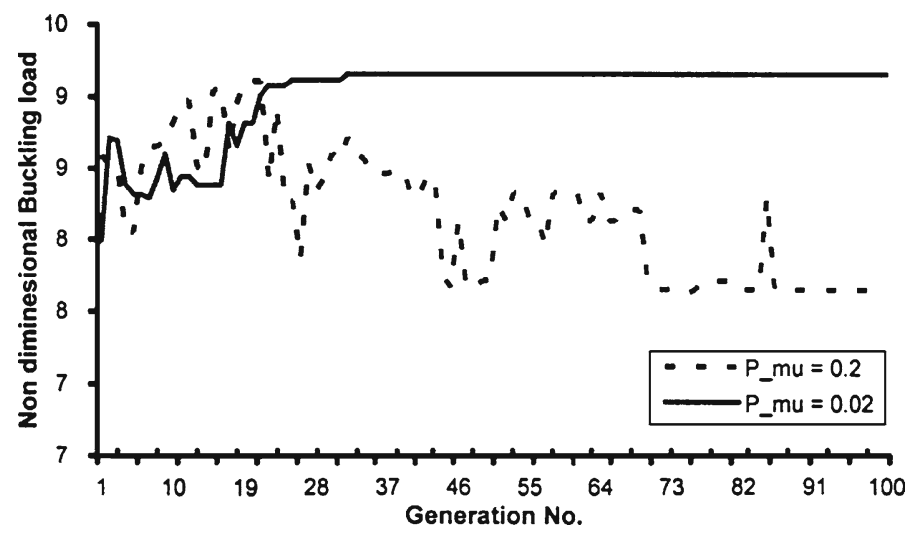

Figure 8. Non-dimensional buckling load versus number of generation (square plate). 


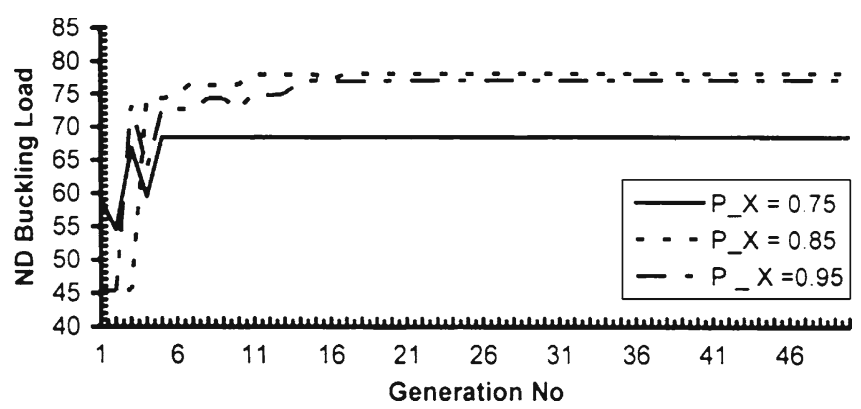

Figure 9. Non-dimensional buckling load versus number of generations (square plate).

\section{Conclusions}

The following conclusions can be made on the basis of the limited study:

(i) For thick anti-symmetric laminates, the non-dimensional optimum buckling load decreases with increase in aspect ratio and increase in fibre orientation angle.

(ii) There is a decrease in the non-dimensional buckling load of a symmetric laminate in the presence of cut-out. There is a critical cut-out size with respect to laminate size, where the buckling load exceeds that of plate without cut-out.

(iii) Mutation is clearly needed as a source of variability, but too much of it definitely deleterious.

(iv) For a given number of variables, population size, there exists a critical probability of mutation.

(v) Effect of crossover probability is not significant on the optimum solution.

\section{References}

Anil V 2004 Stability analysis of composite laminates with and without cut-out. M.Tech Thesis, Indian Institute of Technology, Kanpur, India

Bogner F K, Fox R L, Schmit L A 1966 The generation of inter element compatible stiffness and mass matrices by the use of a interpolation formula. Matrix Methods in Structural Mechanics 397-444

Callahan J K, Weeks E G 1992 Optimum design of composite laminates using genetic algorithm. Compos. Eng. 2: 149-160

Chakraborty A 2003 Stability analysis of composite laminates using simple higher order shear deformation theory. M.Tech Thesis, Indian Institute of Technology, Kanpur, India

Deb K 2001 Multi-objective optimization using evolutionary algorithms. John Wiley and Sons

Goldberg D D 1989 Genetic algorithm in search, optimization, and machine learning. Addison-Wesley

Hui D 1984 Shear buckling of anti-symmetric cross-ply rectangular plates. Fibre Sci. Technol. 21: 327

Jain P, Kumar A 2003 Post buckling response of square laminates with a central circular/elliptical cutout. Comput. Struct. 65: 119-125

Jones R M 1975 Mechanics of composite materials. Philadelphia, PA: Taylor \& Francis, Second Edition

Kogiso M, Watson L T, Gurdal L, Hftka R T, Nagendra S 1994 Design of composite laminates by a genetic algorithm with memory. Mech. Compos. Mater. Struct. 1: 95-117

Leissa A W 1981 Advances in vibration, buckling and post buckling studies in composite plates, composite structures. Proceedings I ${ }^{\text {St }}$ International Conference on Composite Structures, London: Applied Science Publishers, 312-334

Leissa A W 1987 A review of laminated composite plate buckling. Appl. Mech. Rev. 40: 5 
Lim S P, Lee K H, Chow S T, Senthilnathan R N 1988 Linear and nonlinear bending of shear deformable plates. Comput. Struct. 30: 945-952

Muc A, Gurba W 2001 Genetic algorithms and finite element analysis in optimization of composite structures. Compos. Struct. 54: 275-281

Nagendra S, Haftka R T, Gurdal Z 1992 Stacking sequence optimization of simply supported laminates with stability and strain constraints. J AIAA 30: 2132-2137

Paul C 1998 An introduction to genetic algorithms for numerical optimization. Mini-Workshop on Numerical Methods in Astrophysics, Oslo

Prabhakara D L, Datta P K 1997 Vibration, buckling and parametric instability of plates with centrally located cutouts subjected to in-plane edge loading (tension and compression). Thin Walled Struct. 27: 443-470

Reddy J N 1984 A simple higher order theory for laminated composite plates. J. Appl. Mech. 51: 745-752

Reddy J N 1990 A general non-linear third-order theory of plates with moderate thickness. Int. J. Nonlinear Mech. 25: 677-686

Reddy J N 2004 Mechanics of laminated composite plates and shells: Theory and analysis. Boca Raton, FL: CRC Press, Second Edition

Reddy J N 2006 An introduction to finite element method. McGraw-hill, Third Edition

Reissner E 1945 The effect of rotary inertia and shear on flexure motion of isotropic plates. J. Appl. Mech. 12, A69-77

Singh G 1993 Nonlinear bending, vibration and buckling of composite beams and plates. Ph.D. Thesis, Indian Institute of Technology, Kanpur, India

Sivakumar K, Iyengar N G R, Deb K 1999 Optimum design of laminated composite plates undergoing large amplitude oscillations. Appl. Compos. Mater. 6: 87-98

Srivatsa K S, Murthy A V K 1991 Stability of laminated composite plates with cut-outs. Comput. Struct. 43: $213-219$

Vyas N 2005 Optimal design of composite laminates subjected to in-plane compressive loads. M.Tech Thesis, Indian Institute of Technology, Kanpur

Whitney J M 1969 The effect of transverse shear deformation on the bending of laminated plates. J. Compos. Mater. 3: 534-547

Whitney J M, Pagano N J 1970 Shear deformation in heterogeneous anisotropic plates. J. Appl. Mech. 37: 1031-1036 